\title{
Desenvolvendo a solidariedade no caminho da transição: um ensaio sobre a teoria do socialismo a partir de Marx ${ }^{1}$
}

\author{
Jonas de Oliveira Bertucci ${ }^{2}$
}

\section{Resumo}

Segundo verifica-se nos trabalhos de K. Marx com vista a uma teoria da transição, o socialismo seria uma etapa intermediária para um sistema superior - o comunismo - tornado possível somente após o pleno desenvolvimento das forças produtivas, "missão histórica" do capitalismo. Essa tese se mostrou bastante controversa, posto que a história vem demonstrando que a expansão do capitalismo, nos últimos dois séculos, não foi limitada pelo avanço da técnica a ponto de iniciar um processo de transição fruto de uma intensa reação revolucionária. Neste contexto, a proposta do presente trabalho é discutir alguns aspectos do pensamento de Marx, a atualidade de sua teoria da transição e o processo de crise da reprodução das relações de produção capitalistas na modernidade. Ao final, são discutidas propostas mais recentes que sugerem formas de organização produtiva alternativas a partir das práticas de autogestão, com o título de economia solidária.

Palavras-chave: Capitalismo; Teoria marxista da transição; Economia solidária; Autogestão.

\section{Abstract \\ Developing the solidarity in the path to transition: an essay on the socialism theory based on Marx}

According to the main ideas that one may extract from Marx's works on a transition theory, the socialism would be an intermediate stage for a superior system - the communism - made possible only after the complete development of the productive forces, capitalism's "historical mission". This thesis represents one of Marx's biggest controversies and history has demonstrated that the reproduction and the expansion of the capitalism have not been limited by the advance of the technique - and that neither a transition process would emerge from a sudden revolutionary reaction. In this work, we put on discussion some aspects of Marx's thought, his transition theory and the current process of crisis of the reproduction of the capitalist relations of production. In the conclusions, a series of experiences of self-management with the heading of solidarity economics are discussed.

Key words: Capitalism; Marxist transition theory; Solidarity economics; Self-management. JEL B14, B24, P2.

(1) Trabalho recebido em fevereiro de 2008 e aprovado em fevereiro de 2009. Uma versão preliminar deste artigo foi apresentada no XXXIII Encontro Nacional de Economia da Anpec em dezembro de 2005. Agradeço pelos comentários e críticas do professor João Antônio de Paula na elaboração do mesmo. Realizado com o apoio do CNPq (Conselho Nacional de Desenvolvimento Científico e Tecnológico).

(2) Doutorando em Sociologia na Universidade de Brasília (UnB), Brasília, DF, Brasil. E-mail: $<$ mestrejonas@gmail.com $>$.

Economia e Sociedade, Campinas, v. 19, n. 1 (38), p. 173-200, abr. 2010. 
As criaturas de fora olhavam de um porco para um homem, de um homem para um porco e de um porco para um homem outra vez; mas já era impossível distinguir quem era homem, quem era porco (Orwell, 1945).

\section{Introdução}

A temática da transição do capitalismo para um sistema pós-capitalista é um assunto recorrente no debate marxista. No entanto, Marx pouco escreveu sobre esse tema, dedicando a maior parte de seus trabalhos à análise histórica da transição do feudalismo para o capitalismo e de seu funcionamento. Sua previsão sobre o futuro do capitalismo se limitou a dizer que haveria uma etapa intermediária - o socialismo - que conduziria a um sistema superior - o comunismo -, tornado possível somente após o pleno desenvolvimento das forças produtivas - conhecida "missão histórica" do capitalismo. Essa tese se mostrou bastante controversa, na medida em que a expansão do capitalismo nos últimos dois séculos não foi limitada pelo avanço da técnica a ponto de iniciar um processo de transição, fruto de uma intensa reação revolucionária. Ao mesmo tempo, um novo conjunto de práticas que se reproduzem nas últimas décadas renova esse debate atualmente.

Neste contexto, discutem-se aqui alguns aspectos do pensamento de Marx em torno da teoria da transição. Para isso, foi seguida uma sequência relativamente didática, procurando apresentar diferentes questões que se cruzam constantemente. De início discute-se, em linhas gerais, a base epistemológica da análise marxiana, de modo a apresentar a interdependência inevitável entre conhecimento e prática que delineia sua compreensão de ciência. Em seguida, procura-se situar minimamente as diferentes interpretações sobre os termos socialismo e comunismo. Esta discussão, além de facilitar o debate, abre o caminho para rever a ideia de existência de um possível determinismo em Marx e, enfim, também para aprofundar o que seria considerado uma teoria da transição entre modos de produção. Na quarta parte, busca-se resgatar a importância da compreensão sobre a lei do valor-trabalho, assim como seus limites, no que tange o processo de distribuição da riqueza em sociedades não-capitalistas. A questão da alienação e do processo de conscientização humana através do entendimento de sua condição histórica é tratada na quinta parte, onde procura-se mostrar que essa superação, na prática, não será dada senão quando os indivíduos passarem a realizar sua identidade com a sociedade, principalmente através de uma atividade social fundada sobre uma ampla medida de decisões livres. Por fim, são feitas algumas considerações gerais onde a ideia da autogestão do trabalho, ao nível da economia tomada no seu conjunto, é colocada em pauta como orientação para um projeto de desenvolvimento fundado sobre relações de solidariedade. 


\section{Filosofia e práxis}

A obra de Marx é extensa, abrangente e complexa. Sua vida foi marcada por muitas dificuldades e seus escritos frequentemente permaneceram inacabados. No presente trabalho não se tem a pretensão de abranger a totalidade do pensamento de Marx, nem de se subestimar a complexidade de suas ideias, declaradamente dialéticas (e, por isso, também contraditórias). Entretanto, procura-se fazer uso, aqui, de uma de suas principais lições: a crítica. Aliás, sem a crítica e a autocrítica constante não haveria como se avançar no conhecimento e se aproximar da verdade, em persistente mutação. ${ }^{3}$

Para tanto, nos interessa iniciar essa discussão pela apreensão do conceito de práxis em Marx e, assim, de aspectos sobre sua compreensão de ciência. Como se sabe, antes de iniciar seus estudos em economia e sociologia, Marx desenvolveu sua crítica à filosofia de Hegel e Feuerbach, carregando consigo, a partir daí, traços fundamentais desses dois autores. Nesse sentido, percebe-se, como aponta Henrique Lima Vaz (1982), que a práxis marxiana preservará tanto a exigência racionalista do pensamento de Hegel, quanto o empirismo de Feuerbach. E a fusão entre esses dois aspectos resultará em uma epistemologia original, pois, enquanto o primeiro apresenta uma compreensão dialética idealista da realidade (sem efetivamente transformá-la) e o segundo falha na tentativa de introdução do empirismo na escola hegeliana, para Marx o conhecimento estará constantemente e dialeticamente articulado e envolvido com a prática.

Assim, esta relação, desenvolvida a partir da superação de suas bases filosóficas, refletirá o fato de que a crítica marxista é carregada de juízos de valor, o que não diminui o seu caráter rigorosamente científico. Nas palavras de Henrique Vaz:

(...) se é verdade que Marx entendeu dar à sua crítica da Economia Política um caráter rigorosamente científico, abandonando as considerações filosóficas sobre a "alienação" e obediente à metodologia de uma exigente investigação empírica, não é menos verdade que a crítica da sociedade capitalista só se torna possível a partir de juízos de valor no que diz respeito à concepção do homem e que conduzem inevitavelmente ao problema da alienação (Vaz, 1982, p. 14).

Como explica Mandel (1968), "o ponto de partida de Marx é a contestação prática da miséria operária, que cresce na mesma medida em que crescem as riquezas que essa mesma classe operária produz" (p. 164). Ou seja, é a partir da verificação de aspectos de sua realidade que Marx começa a entender e explicar o mundo (em uma concepção histórica, é a partir da constatação da exploração do homem pelo homem, devido à relação de propriedade privada e à divisão do

(3) Sobre a projeção da crítica e suas implicações na atualidade do pensamento de Marx, ver Paula (2001)

Economia e Sociedade, Campinas, v. 19, n. 1 (38), p. 173-200, abr. 2010. 
trabalho). Tais questões culminam, necessariamente, na concepção de alienação, quando a hegemonização do modo de vida capitalista faz com que seja natural o fato de o homem não ter mais propriedade sobre os produtos de seu trabalho, enriquecendo outros com os seus próprios produtos; quando o trabalho "se torna trabalho em proveito dos que não trabalham" (Mandel, 1968, p. 164). Assim, a ausência de juízos de valor na análise de Marx é impensável, e sua negação (como cada vez mais se procura fazer em Economia, vale lembrar), constitui uma ambiguidade - se não um retrocesso.

Com efeito, a constatação da desigualdade que vinha sendo produzida pelo advento do capitalismo se dá antes mesmo de Marx e Engels, ainda no século XVIII e XIX, quando os primeiros representantes do socialismo começam a expor as graves feridas daquele sistema. Sem dúvida, a obra $O$ que é a propriedade?, de Pierre-Joseph Proudhon (de 1840) e as diversas experiências cooperativas de Robert Owen, além dos trabalhos de Fourier e Saint-Simon, têm forte influência no futuro desenvolvimento da teoria da mais-valia. Entretanto, esses primeiros socialistas acabaram sendo classificados como utópicos, por acreditar, assim como Tomás Morus, ${ }^{4}$ que seus sistemas seriam a forma mais perfeita possível de organização da sociedade. ${ }^{5}$

\section{Socialismo, socialismos}

O socialismo antes de Marx e Engels apresentava-se como um movimento disperso e limitado - e ainda hoje não há um conceito consensual de socialismo. Com efeito, o desenvolvimento do método dialético, a introdução de elementos da dinâmica dos processos históricos, em contraposição à estática positiva da metafísica, e a concepção materialista da história trouxeram elementos fundamentais para a superação, tanto teórica como prática, dos limites do socialismo até o século XIX. O marxismo permitiria, assim, um avanço imenso na compreensão sobre a dinâmica do sistema capitalista, até então insuficiente (ou equivocada). Ou seja, em Marx, não há rastro de utopismo, pois não cria uma

(4) Escritor que cunhou o termo "utopia" [do grego $u$ - sem; topos - lugar], ainda no século XVI, para dar nome a sua ilha fictícia em A Utopia (de 1516), romance que representou uma das maiores críticas da sua época. Vale lembrar que os trabalhos dos socialistas chamados utópicos, e suas teorias e práticas, variavam muito entre si, sendo um perigoso erro considerá-los como um conjunto uniforme e "homogêneo". O que há de comum entre eles, além da forma árdua e direta com que apontam os problemas sociais de sua época (mostrando que as soluções aplicadas até então estavam longe de sua verdadeira causa e essência) é que as aplicações de seus projetos, expressão da "verdade absoluta", não causaram a revolução que eles acreditavam que causaria.

(5) Segundo Engels, esses primeiros socialistas acreditavam ser possível descobrir as soluções dos problemas sociais a partir de um intelecto brilhante, como se fossem problemas técnicos ou educativos. Atuando em prol de toda a humanidade e não como representantes de uma classe, não levavam em conta (nem poderiam levar) o processo de desenvolvimento histórico do capitalismo, a centralidade da luta de classes e o papel do proletariado. 
'nova sociedade', mas estuda o processo histórico e a forma como uma nova sociedade pode nascer a partir da velha. Como afirma Engels:

Desse modo, o socialismo já não aparecia como a descoberta casual dum ou outro intelecto genial, mas como o produto necessário da luta entre as duas classes formadas historicamente (...). A sua missão já não era elaborar um sistema o mais perfeito possível da sociedade, mas investigar o processo histórico econômico de que, forçosamente, tinham que resultar essas classes e o seu conflito, descobrindo os meios para a solução na situação econômica assim criada (...). Com efeito, o socialismo anterior criticava o modo de produção capitalista $e$ as suas conseqüências, mas não conseguia explicá-lo nem podia, portanto, destruí-lo ideologicamente; nada mais lhe restava senão repudiá-lo, pura e simplesmente, como mau (Engels, 1985 [1880], p. 53).

Portanto, segundo Engels, a construção de bases mais sólidas para uma teoria e uma práxis do socialismo só seria possível com a descoberta (que deveríamos a Marx, vale lembrar) do segredo da produção capitalista, a saber: o capitalista compra a força de trabalho do trabalhador e dela retira mais valor do que lhe custa, se apropria de trabalho não pago e essa mais-valia permite a acumulação cada vez maior por esse capitalista. Estava assim fundado o socialismo científico, que representa a conscientização dos conflitos gerados no modo de produção capitalista, conflitos que "tem suas origens independente da atividade ou da vontade dos próprios homens que o provocaram", e que a concepção materialista possibilita compreender.

Consequentemente, Marx voltou seus esforços antes para a compreensão do capitalismo do que para a formulação de um plano de desenvolvimento do socialismo ou do comunismo (apesar de tê-lo feito de forma dispersa e sem sistematização). Como nos recorda Vânia Bambira, "para os fundadores do marxismo, a temática da transição socialista não chegou a ser objeto específico de investigação". 7 Dessa forma, a concepção básica de Marx era de que as sociedades de classes são fases históricas determinadas do desenvolvimento da produção. E do mesmo modo que, em certo momento da história, o capitalismo se mostrou superior ao feudalismo, futuramente e inevitavelmente a luta de classes conduziria a uma fase de transição para uma sociedade superior, a qual ele via na forma do comunismo. Isso é o que Lefebvre (1978) denominou de uma espécie de teoria da obsolescência das sociedades em Marx. No trecho da carta apresentada a seguir, o próprio Marx afirma:

(6) Cf. Engels (1985 [em 1880], p. 56).

(7) Cf. Bambira (1993, p. 19). Embora não seja objeto deste trabalho explorar a temática nesse sentido específico, vale citar Vânia Bambira quando defende que "é justamente a contribuição de Lênin que fundamenta em definitivo a teoria da transição socialista", enquanto "Marx e Engels lançam cimentos para a fundação dessa teoria, (...) Lênin, retomando e enriquecendo essa base à luz da prática, confere-lhe sistema e consolidação" (Ibidem, p. 10-11). 
O que eu trouxe de novo tem sido demonstrar: 1) que a existência de classes está ligada apenas a determinadas fases históricas do desenvolvimento da produção; 2) que a luta de classes conduz, necessariamente, à ditadura do proletariado; 3) que essa mesma ditadura, de per si, não é mais do que o trânsito para a abolição de todas as classes e para uma sociedade sem classes (...) (Marx, carta a Weidemayer em 1852 apud Bambira, 1993, p. 20).

Antes de discutir mais detidamente as características desse processo, é necessário fazer uma distinção mais clara sobre as diversas acepções de socialismo e comunismo. Sweezy (1973) esclarece que, enquanto o socialismo não possui uma definição amplamente aceita e consensual, o comunismo sim. Segundo o autor, este seria o sistema superior ao capitalismo, desenvolvido historicamente. É possível afirmar, de modo geral, que no sistema comunista: as classes não mais existem; o estado se extingue; as formas perversas de divisão do trabalho são superadas; são abolidas as diferenças entre a cidade e o campo e entre o trabalho manual e intelectual; e a distribuição se faz de acordo com as necessidades da sociedade. Como reforça Rosanda (1973), o pensamento marxista afirma a possibilidade de uma democracia plena e direta somente com a extinção das relações de produção capitalistas e a unificação da sociedade pelo comunismo, através da gestão direta da totalidade do produto social.

De acordo com a forma com que se apresenta essa tese sobre o comunismo, como estágio final de evolução humana, pode se incorrer no erro de se assemelhar este aos sistemas estáticos dos socialistas utópicos. Entretanto, para os que assim o veem, é preciso recordar que "apresentar uma política absoluta para um conhecimento absoluto (..) destrói o pensamento marxista pelas suas raízes". (Lefebvre, 1978, p. 80). A análise marxiana em sua complexidade não possui ambiguidade quanto a isso.

É, portanto, no processo de transição que vai se desenrolar a discussão, visto que a passagem do capitalismo ao comunismo não se daria de maneira repentina, mas por um processo gradual que seria o socialismo. Embora, para todos os marxistas, o socialismo não seja um fim, mas um meio - uma fase intermediária entre o capitalismo e o comunismo -, não há consenso, nem mesmo entre os socialistas, sobre as características dessa fase intermediária. Ou seja, existem diferentes concepções sobre o caminho que conduziria a sociedade a tal sistema que permitiria a liberdade e o amplo desenvolvimento das capacidades humanas ${ }^{8}$ a todos os seus membros.

Entre diferentes alternativas, Sweezy apresenta uma das definições de socialismo (da qual ele mesmo já foi adepto) como aquela caracterizada pela propriedade estatal dos meios de produção e pela ampla planificação da economia, processo ocorrido, por exemplo, na URSS. Segundo se afirmava teoricamente no

(8) Cf. Sweezy (1973, p. 1). 
início dessas experiências, a dinâmica interna provocada por essas condições levaria a sociedade socialista ao comunismo. Entretanto, não existia razão alguma para que o planejamento centralizado e a propriedade estatal dos meios de produção pudessem produzir um movimento ao comunismo. Tal processo deveria caminhar para a anulação de todo poder do estado, o que, vale lembrar, não ocorreu em nenhuma sociedade do século XX dita socialista que estaria, então, atravessando um possível processo de transição.

Para Bambira (1993), sem dúvida essas sociedades reproduziram, apesar do discurso contrário, as relações de produção do capitalismo e não alteraram a condição entre dominantes e dominados, essencial para o alcance do comunismo. Nesse sentido, a "ditadura do proletariado" foi um termo infeliz de Marx, tendo seu sentido original desvirtuado na prática. Foi também utilizado de forma pouco responsável em inúmeras más interpretações a fim de justificar as práticas ditatoriais que não mantinham qualquer relação, que não de alienação, além de não promover nenhuma ação consciente do proletariado.

No que se refere às acusações e interpretações rasteiras que responsabilizam a teoria de Marx por esses processos aberrantes, João Antônio de Paula afirma: "o preço demasiadamente elevado que o marxismo pagou ao stalinismo precisa ser definitivamente superado, e suas lições apreendidas" (Paula, 1994, p. 194). O pensamento de Sweezy completa esta ideia apontando que, em suas palavras, "este concepto tradicional del socialismo es completamente inadecuado como objetivo e critério del logro por parte de um gobierno revolucionario encaminado en la larga via hacia el comunismo" (Sweeze, 1973, p. 9).

Com efeito, como argumenta Sweezy delineando uma crítica a outras propostas socialistas, o controle das empresas econômicas pelos trabalhadores (como no caso da Iugoslávia), se ainda era dominado pelas relações de valor, também não significa uma mudança fundamental. Representaria, para ele, uma espécie de capitalismo coletivo e não socialismo propriamente, onde há apenas uma transformação efetiva para um pequeno núcleo de trabalhadores privilegiados dentro de determinada empresa. Conclui relembrando a conhecida afirmação de Marx de que, em qualquer que seja o socialismo, os trabalhadores não devem apenas tomar posse do aparelho estatal burguês estabelecido, mas devem romper com este e destruí-lo inteiramente, criando uma nova base de ordenação social.

É importante lembrar que, para Marx, e como é expresso em A ideologia alemã (cuja edição completa só foi publicada em 1933), o socialismo não poderia avançar se não fosse um movimento em escala mundial e internacional, e teria início nas sociedades onde as técnicas produtivas estivessem mais desenvolvidas (como veremos adiante), o que não era o caso da URSS ou de Cuba. 
Numa outra perspectiva, a comuna de Paris, apesar de seu tempo curto de existência, é um bom exemplo de processo revolucionário que reflete virtudes de uma experiência socialista. A comuna suprimiu o serviço militar obrigatório, declarou a gratuidade da educação, aceitou a eleição de estrangeiros para cargos políticos (com uma bandeira de integração mundial), limitou a remuneração de seus funcionários (evitando o enriquecimento e o ingresso de políticos movidos por interesses individuais), decretou a separação da Igreja e do Estado, queimou a guilhotina em praça pública, entre outras ações. Enquanto as inúmeras experiências de revolução acabaram por fracassar porque, ao final, perderam todo o seu caráter humanista, a comuna realizou inovações tão profundas que, ao ameaçar o Estado burguês, foi violentamente rechaçada (Marx, 1999).

O termo comunismo, atualmente, não é sequer discutido nessa significação humanista, tendo seu uso sido vulgarizado, principalmente durante o período da guerra fria. ${ }^{9}$ Alguns grupos isolados, liderados geralmente por partidos ou facções radicais, ainda assumem o comunismo, que, para muitos (e algumas vezes mesmo para a esquerda menos "subversiva"), ainda tem um tom de ameaça, não apenas à ordem vigente, mas inclusive às possibilidades de diálogo pacifico. É assim que, no meio acadêmico, embora essa discussão esteja distante do mainstream, há uma preferência clara pelo uso do termo socialismo que, como vimos, adquire diversos sentidos apesar de se apoiar em uma mesma base políticoideológica de evolução e desenvolvimento humano.

\section{Determinismo e transição}

A análise de Marx sobre o capitalismo se faz, portanto, sob a perspectiva de uma sociedade superior, comunista, sendo que a transição emerge como uma resultante lógica e histórica desse processo (Bambira, 1993). É de se notar que Marx e Engels apreenderam a natureza profundamente revolucionária do modo de produção capitalista mais nitidamente - e muito mais lucidamente - do que os próprios intelectuais que viam, nesse sistema, o único caminho para o desenvolvimento. Isso é feito rompendo com a inviolabilidade da propriedade privada, mostrando que a visão "ahistórica" dos economistas clássicos era válida apenas para o sistema capitalista, e que este não existiu sempre e certamente não

(9) O senso comum do cidadão norte-americano há poucas décadas atrás (e talvez até hoje) dizia simplesmente que era preciso lutar contra o "comunismo" (repressor, ateísta e diabólico) em nome da liberdade (do mercado e da propriedade privada). Carla Rodeghero apresenta uma interessante discussão sobre o anticomunismo católico nos EUA e no Brasil durante a guerra fria, mostrando que, mais do que uma manifestação religiosa, a ideologia que mediava a sociedade norte-americana poderia ser considerada uma "religião civil" baseada em questões políticas, econômicas e sociais. Diz a autora: "Assim, a pertença a uma igreja e uma atitude abertamente favorável em relação à religião se tornaram formas de afirmar o American Way of Life, especialmente porque a União Soviética e seus aliados assumiram oficialmente o ateísmo" (Rodeghero, 2002, p. 473). 
será eterno. Marx chega à conclusão de que a conjugação da divisão do trabalho, da propriedade privada e da produção mercantil se torna instrumento de alienação, onde o trabalho, fonte última do valor, se torna trabalho alienado e as relações humanas, consequentemente, relações de alienação (Mandel, 1968, p. 31).

Assim, contrapondo a teoria dominante (e criticando duramente inclusive os socialistas), Marx inicia sua crítica à Economia Política da época, a qual se mostra submersa em uma ideologia que encobre, tal qual uma nuvem de neblina, a realidade da exploração contida na propriedade privada. Essa ciência, "desumana e infame", conforme afirma, não se interessa de fato pelo homem e não dá valor à vida humana, reduzindo o trabalhador a mero custo de produção enquanto trata apenas da produção do lucro dos capitalistas e da renda dos proprietários fundiários. $^{10}$

Por enquanto, nos interessa discutir como Marx destrincha a lógica e o caminho do capitalismo como ninguém antes havia feito, compreendendo seu caráter revolucionário e sua intensa capacidade de expansão e reprodução de suas relações de produção. Após a descoberta da América e o aumento da concorrência pelas colônias, quando a renda fundiária começa a cair, os comerciantes, impulsionados pela revolução industrial e pelo aumento de produtividade com a divisão do trabalho, se transformam na burguesia. A nova classe revolucionária domina a grande fábrica moderna e toma a frente dos antigos grupos latifundiários. Enquanto regionalmente o campo se submete à cidade, a nível global os Estados-nações são obrigados a se apropriar do modo de produção fabril e mover todos os recursos possíveis para desenvolvê-lo - em condições e momentos diferentes, evidentemente. Dessa forma, o capital, movendo os homens e as nações através da concorrência pelos mercados mundiais, possibilita um avanço colossal da ciência, da tecnologia e de sua aplicação para o desenvolvimento da produção mercantil. Para Marx, tal impulso dado às forças produtivas não poderia ocorrer senão devido ao capitalismo. ${ }^{11}$

Mas não é possível se considerar de modo tão determinístico que a evolução tecnológica teria imposto a revolução capitalista. Um longo caminho teve que ser percorrido para que a opção industrial vigorasse frente à produção simples de mercadorias, bem além da superioridade competitiva para produzir melhor e mais barato. Foi necessário desmantelar todo o aparato tradicional de

(10) Cf. Mandel (1968, p. 45). Embora no século XX, a busca pelo pleno emprego possa ter se tornado uma das principais questões na economia (em parte, devido a críticas desse tipo), ainda sim, reluta-se em questionar as condições sociais e históricas que determinam a situação dos indivíduos na sociedade.

(11) Cf. Mandel (1968, p. 59). Essa é a base dos trabalhos de Schumperter, quando analisa a forma como, no capitalismo, o desenvolvimento das forças produtivas por meio da corrida por inovações (que gera o processo de destruição criadora) é conduzido pela busca do lucro extraordinário, permitindo a acumulação de capital. Faz isso otimizando efetivamente suas forças, que incluem, sem escrúpulos ou qualquer consciência, também a guerra, o avanço do imperialismo e a devastação da natureza. 
regulação e distribuição do produto social, que impedia a livre iniciativa e a livre concorrência dos mercados. Segundo Singer, "a partir do abandono das regras que protegiam o antigo regime de produção, o capitalismo teve o caminho livre para se tornar o modo hegemônico de produção" (1998, p. 62). Novas regras, hoje bem conhecidas, com base no laissez-faire e na ideologia do individualismo e da relação monetária, foram formuladas, deixando "a solidariedade social relegada ao âmbito privado e íntimo da religião". 12

No entanto, como coloca Marx, o capital não pode crescer sem desenvolver o proletariado - enquanto a concentração de riquezas nas mãos de uma classe aumentava, a concentração da miséria crescia na mesma proporção para outra classe. E é então que as "armas" da burguesia, usadas na luta contra o feudalismo, se voltariam contra ela mesma. Por um lado, pela criação de uma classe, que, ficando em condições cada vez piores, se torna revolucionária, e por outro lado, pelo fato de que esse desenvolvimento brutal da produção acaba gerando as crises mais contraditórias (Mandel, 1968, p. 59-60). Chega um momento em que o crescimento brutal das forças produtivas entra em contradição com as suas relações de produção, quando estas impediriam a acumulação e a reprodução do capital. A luta dos trabalhadores pela defesa dos salários se transformaria até se tornar uma luta política contra o trabalho assalariado e pela criação de uma nova sociedade, fundada na apropriação coletiva dos meios de produção e na associação livre de todos os produtores.

Nesse sentido, começa a ficar mais clara a visão de Marx sobre a possibilidade do surgimento de uma sociedade superior à sociedade capitalista. Porém, para ele, essa sociedade só poderia vir a surgir com o alto nível de desenvolvimento das forças produtivas possibilitado pelo capitalismo, o que permitiria a satisfação de todas as necessidades dos indivíduos. À medida que o capital provoca o desenvolvimento científico e tecnológico e aproxima o processo produtivo da automação, a contradição entre o tempo cada vez menor de trabalho vivo necessário e a apropriação de mais-valia se manifesta, engendrando a crise. Vale retomar uma citação clássica do polêmico prefácio de Contribuição à crítica da economia política. Ao que tudo indica, não se poderia expressar melhor a questão:

O modo de produção da vida material condiciona o processo da vida social, política e espiritual em geral. Não é a consciência dos homens que determina sua existência. A um certo nível de desenvolvimento, as forças produtivas materiais da sociedade entram em contradição com as relações de produção em vigor, ou - o que não passa

(12) Cf. Singer (1998, p. 62). Como se sabe, no ocidente a própria economia de mercado não teria sido legitimada, institucionalizada e implementada se não tivesse o apoio maciço do Estado no século XIX. Para se chegar ao livre mercado foi necessária uma longa estrada, aberta pelo Estado, para garantir seu "livre" funcionamento. De espontâneo e natural não há nada nesse processo. Para uma interessante análise dessa questão e o papel do Estado na construção dos mercados, ver Nee (1999). 
de uma expressão jurídica das mesmas - com as relações de propriedade, no seio das quais elas se moviam até então. De formas de desenvolvimento das forças produtivas, estas relações se transformam em grilhões das mesmas. Começa então um processo de revolução social. Com a mudança da infraestrutura econômica toda a imensa supraestrutura se revoluciona mais rápida ou mais vagarosamente (Marx, 1974, p. 13).

É necessário ainda precisar que não é possível pressupor um determinismo automático entre o grau de desenvolvimento da indústria e o grau de consciência de classe para o alcance do socialismo, assim como esta conscientização não se daria, para Marx, de forma retilínea. Existem evidentes relações dialéticas entre esses dois desenvolvimentos, até surgirem condições favoráveis à derrubada do capitalismo. Marx atribui ao proletariado o papel-chave do sucesso do socialismo, o que mostra que o essencial é saber se as condições objetivas (resultantes do funcionamento do regime) e subjetivas (que fazem com que o trabalhador se considere em uma situação inferior e insatisfatória) impulsionam a classe operária, periodicamente, para o caminho de uma contestação do capitalismo (Marx, 1974, p. 28).

Contudo, é notório que, em Marx, são as condições materiais que dariam as condições ideológicas para a contestação do sistema. Como diz Mandel, para Marx, "o reino da liberdade não começa senão além do reino da produção material. (...) A verdadeira solução residiria em uma verdadeira redução tão radical do tempo de trabalho (do tempo necessário) que as relações entre 'trabalho' e 'lazeres' se encontram totalmente subvertidas” (1968, p. 117). Nesse momento, o trabalho imediato deixaria de ser a grande fonte de riqueza e o tempo de trabalho de ser a medida dessa riqueza. Portanto, o valor de troca deixaria de ser medida do valor de uso. E a abolição do capitalismo seria a condição que permitiria essa redução para um número muito mais elevado de indivíduos (p. 117). Como podemos verificar, há ao menos um tom de determinismo:

Tal revolução não é possível senão nos períodos nos quais estes dois fatores, as forças produtivas modernas e as formas de produção burguesas entram em contradição uns com os outros (...). Uma nova revolução não é possível senão em seguida a uma nova crise. Ela é tão certa quanto esta (Marx apud Mandel, 1968, p. 71).

É na Ideologia Alemã que se encontra uma primeira definição (e depois no prefácio de Contribuição à crítica da economia política) e se veem as primeiras afirmações de que a sociedade deve se transformar por meio de contradições, quando o desenvolvimento surpreendente das forças produtivas faz com que estas se tornem forças destrutivas. Assim, a obra de Marx tem como alicerce analíticometodológico a concepção de que a base e ordem da vida social são dadas pelos seus fundamentos materiais, pela economia. ${ }^{13} \mathrm{~A}$ "descoberta" da economia como

(13) Vale lembrar que, embora ampla, sua teoria não quer dar conta de tudo o que abrange a economia. 
eixo estruturante da anatomia da sociedade civil o permitiu formular sua crítica à sociedade burguesa, porém, pode não ser suficiente para dar base a uma teoria e prática da transição socialista.

Na Crítica ao programa de Gotha, de 1875, Marx oferece princípios para um projeto socialista onde essa visão é explicitada de forma semelhante. Nesse texto, ele identifica o desenvolvimento das forças produtivas e, em consequência, uma situação efetiva de abundância, como condição sem a qual a transformação não seria possível. Como afirma, "quando, com o desenvolvimento diversificado dos indivíduos, suas forças produtivas tiverem se incrementado também, e todas as fontes da riqueza coletiva jorrarem com abundância - só então o horizonte estreito do direito burguês poderá ser totalmente suplantado (...)" (Marx, 2002 [1875], p. 108).

Segundo autores como André Gorz, ${ }^{14}$ o desenvolvimento recente das forças produtivas na modernidade teria tornado possível, pela primeira vez na história da humanidade, a vitória da liberdade sobre a necessidade, já que cada vez menos trabalho é necessário para dispor aos indivíduos tudo o que é útil e necessário à vida. Dadas as condições materiais presentes, as portas estariam abertas para se revolucionar a superestrutura e as condições subjetivas.

No entanto, é possível perceber certa incoerência nessa ideia. O próprio Marx compreendia que as necessidades fisiológicas (que, de acordo com a produção mundial de alimentos, desde sua época já poderiam ser satisfeitas) são substituídas, de acordo com o processo de desenvolvimento, por necessidades adquiridas socialmente, historicamente criadas (logicamente, estas não crescem apenas para o proletariado, mas também para a burguesia). Destarte, a cada dia novas necessidades são criadas e, apesar de aumentar a quantidade absoluta de bens que o trabalho pode comprar, estes suprem cada vez uma porção menor das necessidades criadas, o que tornaria cada vez mais inevitável a pauperização, ao menos relativa, do proletário. A conclusão é de que, dentro dessa dinâmica do capitalismo, se por um lado a abundância é necessária para o socialismo, por outro, nunca será satisfeita - além de que não é tão trivial que a pauperização acabe engendrando uma revolução. ${ }^{15}$ Com efeito, se é justamente esse

(14) No trabalho de Miguel (2006) é feita uma interessante resenha sobre o projeto de Gorz e diversas alternativas e utopias pós-socialistas.

(15) Nas últimas décadas, após a crise do fordismo, o capitalismo parece demonstrar que nem mesmo necessita mais da manutenção de um exército de reserva para reproduzir-se. De fato, antes os excluídos faziam parte da população trabalhadora desempregada e marginal, dentro de um processo determinado. Hoje se pergunta: quem são os excluídos? Na verdade não são excluídos, pois não se pode afirmar que foram incluídos, já que nunca teriam feito parte do desenvolvimento do capitalismo central. Têm grande peso na população, mas não participariam do circuito de consumo, de produção ou financeiro do capitalismo global, senão marginalmente. Por isso, Lefebvre (1978) aponta que a possível crise não mais se caracteriza como uma crise no processo de acumulação, mas sim se apresenta na dificuldade do capitalismo em reproduzir suas relações de produção. 
desenvolvimento material que abriria caminho para a transição, quando esta seria possível, já que a abundância não é possível?

Ora, Marx não "revelou" claramente como seria esse processo de superação do capitalismo (e de fato, não tratou o tema de forma sistemática). Em alguns momentos, apresentando traços não-deterministas, afirma que esta superação está indefinida, sendo resultante do processo de constantes lutas de classes, de uma aposta na construção de um mundo com igualdade e liberdade, como interpreta João Antônio de Paula (1994; 2001). Em outros momentos, apresenta um determinismo marcante ao afirmar que a superação do capitalismo é um processo histórico inevitável e será possível quando este cumprir sua missão histórica de desenvolvimento das forças produtivas.

Afinal, o alcance de uma sociedade superior será um processo natural, do qual a nós, homens comuns, resta apenas esperar com paciência? Ou é uma transformação a ser conduzida por nossa ação direta e consciente? As respostas de Marx são diferentes em diferentes etapas de sua vida, porém não necessariamente ambíguas. Enquanto podemos perceber claramente nos texto do jovem Marx uma visão mais idealista e revolucionária, típica de um jovem engajado impaciente para realizar as mudanças que pensa serem necessárias, o velho Marx se mostra mais maduro, sisudo e mais conformado (apesar de não perder o romantismo) quanto ao longo tempo necessário para se projetar mudanças radicais - afirmando inclusive a necessidade da passagem por esse sistema destrutivo e predatório - rumo a uma nova ordem nas relações humanas. Talvez de modo ainda um pouco especulativo, mas respondendo a esse possível conflito entre o jovem e o velho, parece-nos aceitável sintetizar essas visões numa fusão entre determinismo e nãodeterminismo. Em outras palavras, a evolução histórica das sociedades a conduz a uma situação - inevitável - em que se atingirá a sociedade superior (esse é o lado determinístico); porém, o tempo e as condições em que isso se dará são imprevisíveis, só podendo se revelar historicamente, e ainda dependeriam - aí sim - do resultado não de apenas uma luta genérica de classes, mas de diversos conflitos e diversas vitórias e derrotas em diferentes níveis, escalas e condições histórico-culturais (esse, então, é o lado não-determinístico). Daí a importância de se ver que em Marx (e isso vale para Marx em qualquer idade) as mudanças, necessárias, só virão da ação - da práxis - e quanto antes e de forma mais decisiva e intensa essas ações forem tomadas, mais próximo se estará desse estágio.

Outra questão a se ter cuidado na abordagem é o fato de que, em Marx, não se pode considerar que o indivíduo é totalmente constrangido pelo meio social, mas sim que ele se libertaria na medida em que tomasse consciência de sua situação histórica. Assim, aponta que a sociedade é, sem dúvida, produto da ação recíproca dos homens. No entanto, estes não são livres árbitros de suas forças produtivas, "as quais são a base de toda sua história", resultado da energia prática 
de homens de gerações anteriores, energia esta circunscrita pelas condições em que estes se encontram situados, por uma forma social que existe antes deles. $\mathrm{Ou}$ seja, "os homens fazem sua própria história, mas não a fazem como querem. Não a fazem sob circunstâncias de sua escolha e sim sob aquelas com que se defrontam diretamente, legadas e transmitidas pelo passado" (Marx, 2002. p. 21). A consequência dessa conexão histórica entre gerações é, para Marx, o fato de que a história social dos homens não é senão a história de seu desenvolvimento individual.

Talvez a incoerência aparente seja o grande peso das condições materiais como requisito necessário nessa transformação. "Não se trata (...) de explicar a práxis a partir da ideia, mas de explicitar as formações ideológicas a partir da práxis material; chega-se, em consequência disso, ao resultado de que todas as formas e todos os produtos da consciência não podem ser resolvidos por força espiritual (...), mas só podem ser dissolvidos pela derrubada prática das relações reais das quais brotam essas tapeações idealistas" (Marx, 2005, p. 66). Como colocado no já citado prefácio, estas são somente as conclusões gerais de um longo e penoso trabalho de conscienciosas pesquisas, as quais não tinha dúvidas que gerariam numerosos conflitos.

Antecipando uma hipótese central neste trabalho, é possível relativizar esse posicionamento materialista. Um socialismo verdadeiro, pode-se dizer, no sentido humanista, não parece ser provável se dependente das condições materiais, como numa via de mão única. Ou seja, o socialismo, acredita-se, dependerá de uma opção política e de uma convicção consciente, formada a partir da práxis material, mas orientada pela solidariedade, pela percepção historicamente traçada do outro. E muitas vezes, esta solidariedade se mostra possível como uma ação autêntica somente dentro da falta de condições materiais e não da abundância. Isso não significa que o socialismo depende de um 'voto de pobreza', mas que sua construção requer simultaneamente o desenvolvimento de outra lógica de distribuição e emprego das forças produtivas.

Marx, de forma menos direta, mas dentro de uma lógica semelhante de tal reversão de valores, chega a algo que se assemelha a esta solidariedade. É também na Crítica ao programa de Gotha que se encontra a afirmação: "de cada um segundo suas capacidades, a cada um segundo suas necessidades" (e não "segundo seu trabalho"). Esta frase representa o lema do sistema que propunha e vai além da simples divisão do produto pelo tempo e qualidade do trabalho, o que explicita alguns problemas da concepção simplista da distribuição do produto social segundo o trabalho.

Assim como o direito, que para ser justo deve ser desigual (e não igual), e deve tratar de forma diferente aqueles que são diferentes, também a parte que 
convém a cada um do produto social deve ser desigual em relação ao seu trabalho, que também é desigual (Marx, 2002 [1875]). Para crianças, idosos e deficientes, por exemplo, não pode ser a lei do valor de troca que permitirá a satisfação de suas necessidades. As desigualdades e os privilégios de trabalho ou lazer não podem ser justificados simplesmente pelas diferenças de atividades (Ibidem, p. 39-40). Começa a se delinear uma compreensão e uma forma de pensar a distribuição do produto socialmente construído, que não responderia à lei do valor, mas a outros critérios.

\section{Da aceitação à recusa da lei do valor}

À primeira vista parece contraditório que a teoria do valor-trabalho, originalmente desenvolvida pelos economistas da escola clássica tão criticados por Marx, tenha servido de base para demonstrar a origem da apropriação de trabalho. $\mathrm{Na}$ verdade, de início, Marx rejeitou a teoria do valor de Ricardo. Somente após um aprofundamento de seus estudos econômicos e de uma superação analítica das contradições que ele acreditava ter descoberto nesta teoria, então, foi possível uma mudança de posição. Não por uma possível agitação revolucionária que esta teoria poderia gerar, mas pela superação em termos da reflexão dialética sobre a realidade, da qual a abstração ricardiana (que parecia querer moldar a realidade de acordo com a teoria) poderia expressar apenas uma verdade aparente. ${ }^{16}$

A teoria do valor-trabalho, então, refinada por Marx, expressa a ideia de que o valor das mercadorias é medido pela quantidade de trabalho socialmente necessário para sua produção. Com base nessa teoria, que não é absoluta, mas válida para a análise de uma economia de mercado, Marx pôde demonstrar logicamente que o capitalismo baseia-se na exploração do trabalhador pela apropriação do trabalho excedente. Desse modo, a acumulação de lucro nada mais seria do que a apropriação do que se denominou mais-valia.

Pautados nessa demonstração, e talvez sem compreender toda a essência da teoria do valor, diversos movimentos depois de Marx defenderam o socialismo como o sistema que poderia oferecer uma justa distribuição do produto do trabalho e, assim, impedir o mecanismo de exploração do trabalhador por meio da abolição da propriedade privada. Contudo, o que esses movimentos parecem não ter percebido é que a lei do valor, que determina o valor da força de trabalho, só pode perdurar no capitalismo, onde o trabalhador se torna mercadoria. Esta é precisamente a dificuldade a ser superada, seja das alternativas do movimento sindical, seja das políticas keynesianas. A sociedade produz para gerar cada vez mais empregos, trabalha para gerar mais trabalho e não menos - esta ideologia do

(16) Não surpreende a afirmação de que "numerosos economistas mais conservadores chegassem a considerar a teoria do valor de Ricardo não somente como logicamente incorreta, mas ainda como socialmente perigosa" (Marx, 2002 [1875], p. 49). 
trabalho faz com que este se torne um fim em si e não um meio para suprir necessidades. ${ }^{17}$

Nesse sentido, uma percepção alternativa aponta para a ideia de que, no socialismo, embora pudesse haver melhor distribuição do produto segundo a lei do valor, esta não poderia ser o critério para a distribuição da riqueza, uma vez que se tornaria apenas um princípio ordenador de planificação.

Com efeito, a existência de formas de regulação do produto social, capazes de permitir a existência da coletividade, não depende da lei do valor e da configuração de relações mercantis. Diversos autores mostraram que a produção capitalista, com base na dominação do mercado e na lei do valor, não foi (e provavelmente não será) a única forma de regulação do produto social que se teve no mundo. ${ }^{18}$ Ao contrário, historicamente houveram (e vale lembrar que ainda "sobrevivem") diversas formas capazes de permitir a existência da coletividade que não são baseadas na relação capitalista, ou, ao menos, onde essa relação não está plenamente configurada. Polanyi (1980 [1944]) afirma que "a economia de mercado é uma estrutura institucional, e sempre nos esquecemos disto, que nunca esteve presente a não ser em nosso tempo" (p. 55). O fato da introdução da máquina na Revolução Industrial ter se dado em meio a uma economia de mercado certamente tem íntima relação com os devastadores efeitos provocados na sociedade naquela época. Não há melhor exemplo histórico que mostre, em termos de recursos disponíveis, a contradição que se impõe quando se quer defender que a existência e reprodução da sociedade necessitam das categorias como mercadoria e produção mercantil.

O erro vem desde a geração de economistas pós-Adam Smith que, com o conceito de divisão do trabalho e da ação pelo autointeresse que tenderia a levar o homem a um estado natural de troca, desviaram todo o interesse histórico da economia e marcaram as análises (ou a falta destas) sobre o homem primitivo, que

(17) Aparentemente, as propostas de renda básica, como aquela defendida por Van Parijs (1994), romperiam a ideologia do trabalho ao permitir a escolha do indivíduo em não trabalhar - oferecendo uma renda básica para todos os cidadãos desde o nascimento. Contudo, tais projetos, embora tenham seu mérito, não rompem (aliás, são perfeitamente compatíveis) com a monetarização das relações sociais e não contribuem para a geração de uma nova solidariedade, a qual poderia superar o individualismo da sociedade capitalista, como mostra A. Gorz (Miguel, 2006). Assim, torna-se desapontador o fato de que a proposta de liberdade de Van Parjis ("a liberdade real de levar a própria vida da forma como se desejar") não difere da concepção utilitarista do homem (na máxima benthaniana, "cada indivíduo é o melhor juiz do seu próprio interesse"), desconsiderando a forma como desejos e vontades humanas são formados socialmente. A dificuldade se revela numa visão estanque e fracionada do comportamento humano que considera a realidade individual, em princípio, independente da sociedade e da cultura. Assim, ignora completamente a relação tão cara às ciências sociais entre indivíduo e sociedade.

(18) Nesse sentido, os trabalhos de A. Chayanov, M. Mauss, K. Polanyi, M. Sahlins e P. Clastres, entre outros, são exemplos de estudos que, apesar de manterem suas especificidades, apresentam formações sociais dotadas de certa estabilidade estrutural, nas quais a existência da coletividade não depende absolutamente de relações capitalistas de produção. 
poderiam ser altamente relevantes para os problemas de nossa época. Com efeito, a maioria das sociedades primitivas não possuía um sistema de mercado estabelecido. Para se entender sua formação seria necessário ligar história econômica e antropologia social, algo nunca feito consistentemente (e não seria falso dizer, por longo tempo evitado). Como afirma Polanyi (1980 [1944]), "a Economia do homem está submersa em suas relações sociais" (p. 61), isto é, suas ações não são movidas pelo interesse individual de acumulação material, mas por sua situação social.

Essa conclusão é reforçada pelas conhecidas pesquisas sobre as comunidades na Melanésia, onde inexiste a motivação pelo lucro, o trabalho assalariado ou qualquer instituição baseada em motivações econômicas, mostrando exemplarmente que estas motivações "se originam no contexto da vida social" (Polanyi, 1980 [1944], p. 62). Nessas comunidades, a ordem na produção e na distribuição é garantida por outros princípios, a saber, o da reciprocidade e da redistribuição. Aqui, então, um indivíduo é beneficiado segundo seus atos de virtude cívica, de modo que sua reputação (segundo o cumprimento do trabalho e da oferta dos melhores produtos da colheita para a família de sua esposa, no caso da Melanésia) é de extrema importância para manter o equilíbrio de subsistência familiar. Nesse sentido, os padrões institucionais e os princípios de comportamento se ajustam mutuamente e o sistema econômico é dirigido, fundamentalmente, por motivações não-econômicas.

Numa tal comunidade, é vedada a ideia do lucro; as disputas e os regateios são desacreditados; o dar graciosamente é considerado como virtude; não aparece a suposta propensão à "barganha, permuta e troca" (como sugeria Adam Smith). Na verdade, o sistema econômico é mera função da organização social (Polanyi, 1980 [1944], p. 64).

Para além da reciprocidade e da redistribuição, o trabalho clássico de Marcel Mauss, em especial seu Ensaio sobre a Dádiva, recentemente tem inspirado uma crítica à generalização da concepção utilitarista nas ciências sociais, notadamente encontrada na obra de Allan Caillé. ${ }^{19}$ Tais estudos críticos apontam que existem, dentro de qualquer sociedade, situações em que os homens tomam ações econômicas em favor do outro sem esperar nada em troca, movidos pelo dom ou pela dádiva. Como afirmam Lechat e Schiochet (2003), essas relações não se restringem a grupos familiares ou de amigos, mas se dão também (e talvez mais ainda na atualidade do que antigamente) entre desconhecidos, sem que nem mesmo se veja o resultado da ação. Isso ocorre, por exemplo, quando doações de sangue, ações humanitárias ou trabalhos voluntários são realizados como dádiva, o

(19) Junto com Jacques Godbut, estes dois autores se destacam, tendo fundado o Movimento Antiutilitarista nas Ciências Sociais (MAUSS). O site do jornal do MAUSS recentemente ganhou uma versão em português e espanhol, se transformando em uma revista eletrônica bimestral. Disponível em: $<$ http://www.jornaldomauss.org/>. 
que reforça a inexistência de um contato direto entre doador e receptor. ${ }^{20}$ Nesse processo, podem ser formadas redes de confiança regidas pelo dever de dar, receber e retribuir, nas quais, quando algo é oferecido, não se sabe como nem de que forma poderá retornar. Daí a dialética de que, ao mesmo tempo, a dádiva pode ser interessada e desinteressada. A questão é que, de um modo ou outro, ela é uma construção social.

Na sociedade atual, ao lado da circulação dos bens e serviços no mercado, e da circulação assegurada pelo Estado sob forma de redistribuição, existe um enorme contingente socioeconômico mal percebido, no qual os bens e serviços transitam em primeira instância através dos mecanismos do dom e do contradom. É esse conjunto de fenômenos que agrupamos sob o conceito de economia da dádiva. (Lechat; Schiochet, 2003, p. 86).

Tudo isso para sugerir que o processo de superação do capitalismo e construção do socialismo, enfim, pode ser o processo de formulação de um modelo fundado fora da base da lei do valor, onde o trabalho e a força de trabalho não mais são determinados pelo mercado, como mercadoria, mas resultam de uma lógica bem diferente de interação e compromisso social. Parece-nos plausível apontar essa ideia na mesma direção em que Singer (2003) analisa as diversas experiências que têm se multiplicado, no Brasil e no mundo, sob o título de "economia solidária", que reproduzem relações de reciprocidade dentro dos interstícios do capitalismo.

Para o autor, na sociedade brasileira, o sistema socioeconômico é constituído por diferentes modos de produção que competem entre si. Além do sistema capitalista hegemônico - caracterizado pelo conflito entre capital e trabalho, pelas relações de propriedade e de assalariamento, e cuja lógica é o lucro -, há uma série de formas não-capitalistas de produção. Entre elas, têm-se os seguintes exemplos: a pequena produção familiar, onde não há distinção entre a remuneração do capital e a remuneração do trabalho, apesar de produzirem mercadorias para o mercado capitalista; a produção sem fins de lucro pelos estabelecimentos do Estado, como escolas e hospitais (que empregam assalariados); e, finalmente, os empreendimentos formados por trabalhadores associados em cooperativas e empreendimentos autogestionários ligados a redes de produção e consumo, que formam a economia solidária.

Uma melhor compreensão desde essas experiências até as comunidades primitivas permite perceber que, mesmo com o capitalismo tendo se tornado hegemônico, formas alternativas de produção escapam a ele. Como aponta Paula

(20) Um dos exemplos atuais mais vigorosos de relações de dádiva secundária entre desconhecidos, em escala mundial, pode ser verificado na massiva corrente de solidariedade frente à tragédia asiática do final de 2004, onde milhares de toneladas de alimentos e mantimentos foram enviados em auxílio às vítimas dos tsunamis. Evidentemente, não se pode ignorar a forte influência sensacionalista que os meios de comunicação têm sobre esse tipo de tragédia. 
(2000), o desenvolvimento de uma teoria, ainda inexistente, que incorpore as economias não-capitalistas, é importante inclusive para uma solução adequada ao problema da transformação entre valores e preços em Marx. Com efeito, pode-se buscar ampliar a compreensão do processo de "desconfiguração" da relação capital-trabalho/lucro-salário dentro dessas pequenas experiências, assim como de sua articulação dentro do sistema.

Embora esta configure uma questão fundamental, não se trata neste trabalho de discuti-la pelo viés, por exemplo, daquele abordado por Ricardo Tauille (2001), que pretende entender se a produção através das formas de economia solidária pode ter espaço próprio de sobrevivência sustentável no longo prazo nas economias contemporâneas. Diferentemente, o foco aqui centra-se nas mudanças sociais e econômicas mais gerais, das quais essas formas de reprodução são apenas uma manifestação. Trata-se de compreender, a partir da teoria da transição, possíveis mudanças mais amplas no modo de produção capitalista. Neste sentido, Lefebvre, em A sobrevivência do capitalismo, aposta todas as suas "fichas" na construção do socialismo através da autogestão (que não por acaso é um dos eixos fundamentais das formas de economia solidária).

Lefebvre (1978) aponta que aquilo que sustentaria, ou o que permitiria a reprodução de um modo de produção seria sua capacidade de reprodução de suas relações de produção. Ora, se a sociedade atual se encontra diante de um processo de difusão e aceleração do crescimento de atividades baseadas em relações de produção não-capitalistas, não se pode excluir a possibilidade de ruptura do processo de reprodução do sistema - uma vez que a reprodução de suas relações de produção estaria ameaçada de antemão. Diversas sociedades primitivas - bem como a sociedade feudal, antes hegemônica - não conseguiram manter condições de reprodução de suas relações de produção, sendo sobrepujadas pelas relações capitalistas (de forma impositiva ou não). Assim, torna-se fundamental estudar até que ponto a multiplicação das novas relações de produção, que têm sido observadas, indicam ou não - seja de forma gradual ou revolucionária - um processo de transformação da sociedade.

O elevado grau de desenvolvimento das forças produtivas, proporcionado pelo capitalismo, e o aumento do controle do homem sobre a natureza são frequentemente vistos como um dos possíveis caminhos para essa transformação. ${ }^{21}$

(21) São bastante comuns as afirmações de que um sistema socialista não forneceria incentivos ao desenvolvimento tecnológico, tal como faz o capitalismo, e daí a necessidade histórica deste sistema. Contudo, tais afirmações são no mínimo duvidosas, já que, de um lado, nada impediria tal desenvolvimento numa sociedade socialista entendida na forma como vimos discutindo e, de outro, o elevado grau de desenvolvimento das forças produtivas no capitalismo não significa em absoluto uma maior satisfação das necessidades humanas. Para uma discussão das deficiências do sistema capitalista no que toca o desenvolvimento tecnológico, e uma discussão inicial das possibilidades desse desenvolvimento na economia solidária (por meio dos benefícios advindos do desenvolvimento de fatores como confiança, envolvimento e cooperação), ver o trabalho de Bertucci (2004).

Economia e Sociedade, Campinas, v. 19, n. 1 (38), p. 173-200, abr. 2010. 
Contudo, os critérios para responder às clássicas questões econômicas (o que, quanto, como e para quem produzir) colocadas para qualquer sociedade dependem de fatores complexos que governam seu modo de produção. A alternativa do capitalismo dirigido se mostrou falsa, assim como falharam também as práticas do socialismo burocrático. Assim, torna-se imperativo o desenvolvimento e a visualização de um caminho alternativo de transformação e desalienação, que apenas parece ser possível com o aumento gradual de sua capacidade efetiva de autogestão.

\section{Alienação e Solidariedade}

Todos os homens e todas as sociedades até o tempo atual apresentaram alguma forma de alienação, em maior ou menor grau, de modo mais ou menos explícito, ou ainda defendido por uma ideologia religiosa. Contudo, em seu desenvolvimento histórico, a humanidade foi capaz de ampliar constantemente as forças produtivas sociais, assim como seu conhecimento sobre o mundo e sobre si mesma. Na idade média, o conhecimento era mais localizado, e a invasão de uma comunidade por outra podia levar à destruição de toda uma cultura original. Já atualmente, o conhecimento é cada vez mais global (embora o desrespeito cultural não seja menos violento), e invenções e descobertas são transmitidas com enorme rapidez. A capacidade de generalização da compreensão científica do mundo cresce continuamente e marca a história dos últimos séculos.

O fato é que o conhecimento humano, de forma geral, avançou consideravelmente. E esse avanço pode e deve ser pensado não apenas na forma positivista - sobre o conhecimento técnico e científico em si -, mas também no que tange questões sociais que envolvem, necessariamente, juízos de valor. Basta verificar as mudanças nas condições de trabalho que, nos períodos de escravidão ou de servidão eram absurdas em relação aos padrões de hoje, mas aceitas naturalmente. $\mathrm{O}$ fato da exploração e da luta de classes se apresentarem hoje em dia de forma fetichizada pode significar, no mínimo, que a situação de tempos históricos passados (quando a barbárie era de alguma forma livre) não é mais legitimada socialmente, e que um mecanismo mais complexo é necessário para se manter a condição de dominantes e dominados. Por outro lado, também se poderia afirmar que a superação da exploração hoje se torna muito mais difícil, já que seus mecanismos atuais são muito mais complexos. A conclusão muda, ao final, apenas de acordo com o ângulo que se quer observar.

Possivelmente - e aqui a posição é ainda mais uma previsão hipotética sobre o futuro -, quando houver uma compreensão generalizada da condição de exploração atual, a venda do trabalho como mercadoria será algo tão abominado quanto é a escravidão pensada hoje (apesar de sabermos que ainda hoje existe trabalho escravo). Este seria um dos caminhos lógicos, talvez determinístico, 
quando se pensa no desenvolvimento da sociedade como um processo natural para a superação da alienação e para o alcance do socialismo. Essa perspectiva é um tanto clara:

Nosso método põe em evidência os pontos nos quais deve introduzir-se a análise histórica, ou nos quais a economia burguesa, como mera forma histórica do processo de produção, aponta para além de si mesma, para os modos procedentes de produção históricos. (...) Esta análise correta leva de qualquer maneira a pontos nos quais, prefigurando o movimento nascente do futuro se insinua a abolição da presente forma das relações de produção [entre elas, o assalariamento]. Se por um lado as fases pré-burguesas se apresentam como pressupostos puramente históricos, ou seja, abolido-se a si mesmas e, portanto, como estabelecendo os pressupostos históricos para um novo ordenamento da sociedade (Marx, Elementos fundamentales para la critica de la economia politica apud Bambira, 1993, p. 25).

A busca pela superação da alienação é, assim, a busca pela completa consciência e libertação do homem e do entendimento de sua condição histórica. Esse caminho histórico da emancipação e da compreensão da essência humana é justamente o caminho que poderia conduzir a seu pleno desenvolvimento. Não sem conflitos, é óbvio, mas em meio a uma série de lutas de classe, cujos resultados, que só podem ser determinados historicamente, darão a forma e o tempo com que se poderá realizar tal emancipação. Não que o homem alienado seja aquele que "perdeu sua essência", mas é aquele que ainda não a compreendeu em sua totalidade..$^{22}$ Essa busca é, pois, o caminho para a desalienação. E quando se fala sobre a busca pela emancipação, isto é, sobre liberdade, justiça ou igualdade, uma qualidade se faz absolutamente necessária para tornar esse caminho possível: a solidariedade. Na ausência da solidariedade, ou seja, sem a preocupação frente ao outro refletida em ação (que, não se pode esquecer, pode ser crítica e raciocinada), nenhum de tais objetivos (socialistas) é justificado. Sem dúvida é uma visão otimista, mas de forma alguma utópica.

Perante essa questão, reforçada pela fatalidade da experiência soviética, há um ceticismo generalizado nas possibilidades para o fim da alienação e para o desenvolvimento de uma sociedade solidária. Tentando resgatar a ideia de que o caminho para o comunismo passaria necessariamente pela estatização dos meios de produção, poderia-se argumentar que nas sociedades de base socialista, as condições reais para o fim da alienação - a infraestrutura material e social - não estariam suficientemente desenvolvidas. Com efeito, tanto a compreensão da inevitabilidade da alienação quanto a justificativa de que as condições para seu fim

(22) Afirmar que haverá um momento e uma sociedade sem alienação, sem exploração e sem classes, possivelmente socialista, não significa dizer que surgirá o homem completo e uma sociedade perfeita, e não implica no fim (em termos literais) da história, mas sim no início da "verdadeira história", aquela passível de ser construída de forma consciente e planejada. 
ainda não estavam dadas (pela via do desenvolvimento das forças produtivas) dificultam um olhar crítico e propositivo.

Concepções desse tipo são controversas e podem parecer tentativas frustradas de resgatar o marxismo por vias imperfeitas (afinal, pode-se perguntar: como é possível saber quando as forças produtivas estão suficientemente desenvolvidas?). A superação do capitalismo e da ideologia capitalista, embora deva ser um processo mundial, não se daria para todos os indivíduos de uma só vez, mas por um processo de evolução da sociedade em seu conjunto. Processo em que forças político-ideológicas estarão sempre se debatendo, movidas para frente e para trás.

Assim, essa superação, na prática, não será dada senão quando os indivíduos passarem a realizar sua identidade com a sociedade, principalmente através de uma atividade social fundada sobre uma ampla medida de decisões livres, o que implica não somente uma autogestão integral do trabalho ao nível da economia tomada no seu conjunto (no processo de produção, de distribuição e de consumo), mas ainda um enfraquecimento do Estado e o desaparecimento de todas as relações humanas fundadas na coação e na opressão (Mandel, 1968, p. 196197). Em outras palavras, tal condição implica falar em um projeto social que se funda na construção e no desenvolvimento amplo e incondicional de relações de solidariedade.

\section{Considerações finais: por uma outra transição}

Não restam dúvidas de que a forma que Marx dá ao processo de transição, com toda a ênfase no desenvolvimento das forças produtivas como condição necessária e natural no caminho do socialismo, deve ser relativizada. Principalmente quando retomamos a sua própria perspectiva de emancipação humana e desalienação. É ao menos estranho que o alcance de uma sociedade socialista, solidária e coletivista, só possa ser alcançada em meio à abundância de condições materiais. Ora, qual o mérito de tal emancipação e qual o esforço evolutivo? A ideia de que o homem só começará a ajudar efetivamente e sistemicamente um ao outro, que o trabalho só será verdadeiramente livre, e que só cessará a alienação quando o desenvolvimento das forças produtivas for tal que possa suprir todas as necessidades humanas (ou seja, que o socialismo depende de uma condição onde ninguém necessita abrir mão de nada) gera um grande embaraço político e ideológico. Se não fosse uma parte pouco desenvolvida do trabalho de Marx, essa concepção pareceria identificá-lo com a fraca teoria utilitarista (vide homus economicus) dos economistas "vulgares", por ele mesmo tão criticados. Certamente não se fará, aqui, tal acusação. 
Não foram poucos os autores importantes que tentaram continuar esse trabalho, reafirmando as possibilidades de um processo de transição para um sistema superior ao capitalismo, que merecesse ser chamado de socialismo. Contudo, as estratégias para isso poucas vezes foram traçadas de modo preciso. Resistindo a essa tendência, Paul Singer, repensando o socialismo em Uma utopia militante: repensando o socialismo (de 1998), coloca questões importantes em jogo.

Singer afirma que a teoria de Marx, pautada nas inter-relações entre a infra e a supraestrutura, revela com muita acuidade a dinâmica da revolução capitalista, na medida em que explica a longa passagem do feudalismo ao capitalismo. $\mathrm{Ou}$ seja, quando as forças produtivas entram em contradição com as relações de produção, o desenvolvimento de uma nova base material (nas brechas do feudalismo) instaura uma revolução nas suas relações sociais e institucionais, formando e dando hegemonia às relações capitalistas. Na esteira do pensamento de Godelier (1986), a análise marxiana, de forma mais consistente e estruturada, com base na concepção materialista, é elaborada em primeiro lugar para explicar a queda do feudalismo e o surgimento da formação capitalista. A partir daí, admitese a constituição dos primeiros fundamentos para se desvendar, de forma mais geral, as leis "científicas" que regulariam o surgimento, a evolução e o desaparecimento de um dado organismo social, assim como a passagem para um sistema posterior.

Contudo, por si só a mesma teoria não dá conta de explicar uma (possível) revolução socialista. Tal revolução social, marcada por diversas conquistas - como a legalização dos sindicatos, a regularização das cooperativas, a previdência pública até o sufrágio universal, assim como os recentes movimentos de autogestão operária, a generalização da educação gratuita, as mudanças nos hábitos de consumo, a preocupação ambiental, o desenvolvimento de atividades criativas, da ciência, das artes, os projetos reinserção social dos egressos do sistema prisional por cooperativas sociais, etc. -, representa uma transformação supraestrutural muito clara, e que não foi condicionada pelo desenvolvimento das forças produtivas, mas por reações de trabalhadores e de diversos segmentos sociais contra os prejuízos acarretados pelo capitalismo. Tais movimentos estiveram presentes em toda a história do capitalismo, independentemente do nível de desenvolvimento das forças produtivas.

Essa reação se transforma em movimento político, que em diversas fases da história produziu diferentes formas alternativas ao capitalismo de organização social e econômica. Para Singer, "O fracasso do 'socialismo realmente existente' revelou que o socialismo sem aspas terá de ser construído pela livre iniciativa dos trabalhadores em competição e contraposição ao modo de produção capitalista dentro da mesma formação social" (Singer, 1998, p. 9, grifo nosso). Sua 
perspectiva de socialismo, embora tenha base em Marx, se difere de forma tênue quando defende que uma possível transferência dos meios de produção aos trabalhadores

não pode ser decretada de cima para baixo, mas tem que ser conquistada de baixo para cima, e dentro do capitalismo. E essa conquista não pode deixar de levar muito tempo, pois implica em uma verdadeira revolução cultural protagonizada pelos trabalhadores que se transformam, por sua própria iniciativa, de dependentes assalariados - ou ex-assalariados desempregados - em empreendedores coletivos (Singer, 1998, p. 11, grifo nosso).

Daí a necessidade de se separar os conceitos de revolução social e revolução política.

As revoluções políticas, tanto as burguesas como as proletárias, são episódios bem delimitados no tempo, quase sempre marcadas por um processo violento, mas que, ao final, implementam não apenas uma mudança de governo, mas de sua gestão e das relações de poder entre o estado e a sociedade civil, introduzindo inovações institucionais que difundiram novos padrões de estado e perduraram por longo tempo. ${ }^{23}$ São fundamentalmente diferentes, diz Singer, das duas grandes revoluções sociais em curso: a revolução capitalista e a revolução socialista. Estas "constituem processos de mudança entre formações sociais, cada uma das quais é caracterizada pela hegemonia de um modo de produção, que the empresta o nome" (Singer, 1998, p. 18-19, grifo nosso).

Desse modo, a revolução social capitalista não é um fato delimitado no tempo, mas se deu desde o surgimento do capitalismo nas brechas do modo de produção feudal e subordinado a este, até, com a revolução industrial, se tornar dominante. É este mesmo sentido que nos oferece Marx no prefácio de Para a crítica da economia política, ao afirmar, como vimos, que o capitalismo haverá de ser superado historicamente. Entretanto, é muito difícil julgar até que ponto as diversas atividades não-capitalistas que se reproduzem nos interstícios do capitalismo poderão se mostrar, futuramente, como um modo de produção superior, completando uma nova revolução social (a socialista).

Com efeito, a discussão da transição está relacionada à condição necessária da participação da classe trabalhadora e no desenvolvimento da autogestão, que, para Lefebvre (1978) representa uma solução original para o

(23) Nesse sentido é que se deram tanto as revoluções burguesas (entre as principais, a Revolução Inglesa, a Revolução Americana e a Revolução Francesa) quanto as revoluções proletárias (a Comuna de Paris, a Revolução Russa e a Revolução Chinesa). O que parece contraditório é que, enquanto as primeiras (de certo modo, representantes da virtuosidade do capitalismo) foram as que possibilitaram a difusão de ganhos sociais inegáveis como a Declaração Universal dos Direitos Humanos, as segundas (com exceção da Comuna de Paris) acabaram representando novos sistemas políticos baseados na autoridade e na repressão ditatorial (o que sem dúvida alguma desfez qualquer traço que poderiam conter do pensamento socialista original). 
problema da socialização dos meios de produção, primeiramente posto por Marx. A autogestão teria potencial conceitual e prático para evitar as dificuldades que surgiram nas experiências autoritárias do planejamento centralizado. Segundo Lefebvre, uma possível transição não segue a revolução política, como se daria na prescrição de Marx. Ela a precede, o que demanda urgentemente um projeto concreto e global por uma sociedade nova e qualitativamente diferente, que vai além das demandas comuns por trabalho ou pela melhoria da qualidade de vida. É um projeto que deve estar em constante revisão e que tem grandes chances de falhar, já que os novos "valores" não são impostos, são propostos (Lefebvre, 1978, p. 91). Embora esta transição traga à tona a questão da participação (e sem autogestão, a participação não tem significado real), ela traz também diversos (e novos) problemas.

Em sintonia com o ideário lefebvriano, o projeto da economia solidária tem sua base na autogestão. Este projeto pode estabelecer uma rede de intercâmbio e reforço mútuo a partir das bases da sociedade, que não se limite apenas - e em hipótese alguma - a um projeto de administração das questões econômicas. Tal proposta necessitará de uma nova pedagogia social, ${ }^{24}$ uma nova prática social em todos os espaços em que a vida se coloca, das relações entre os homens e destes com a natureza. "O que ela [autogestão] determina não é um estado, mas um processo, no qual novos problemas são colocados e devem ser resolvidos na prática social", ${ }^{25}$ então, culmina em uma nova ordem social, corroendo a velha superestrutura na qual é erguido o estado atual, redefinindo o socialismo.

Este socialismo só será possível quando a construção da visão social do homem de natureza egoísta for superada, quando se desenvolver socialmente um sentimento generalizado de solidariedade, permitindo que se valorize a disposição a servir gratuitamente. Este grau de autogestão não resulta, portanto, de uma mudança da condição infraestrutural, mas de uma transformação política, moral e simbólica. ${ }^{26}$ Assim, a solidariedade não pode ser assistencial e acrítica, mas deve ser fruto da percepção e da compreensão de uma condição histórica, quando o desenvolvimento tecnológico poderá ser diretamente voltado para o benefício de toda a humanidade, resultado de uma verdadeira opção, por ela definida e gerida.

Com efeito, muito ainda há de ser realizado, pois se é possível surgir hoje a percepção de que a economia solidária não clama pela revolução (no sentido que

(24) Sobre a relação entre economia solidária e pedagogia, é interessante conferir a coleção recentemente lançada sob o título Economia solidária e educação de jovens e adultos, organizada por Sônia Kruppa (2005).

(25) Cf. Lefebvre (1978, p. 125. Tradução nossa).

(26) Apesar de Marx e Engels diversas vezes anteverem de forma precisa processos históricos, quando mostraram que uma crise impulsiona uma revolução, este não parece ser o caso da revolução provocada por um possível desenvolvimento da economia solidária. O liberalismo, o desemprego e a miséria ajudam, porque fazem com que as pessoas sem opções busquem a economia solidária, mas esta não é a essência da questão. 
ficou marcado pelo marxismo), tampouco significa a desilusão de Max Weber. Mannheim afirma que o radicalismo da proposta comunista menosprezou as dificuldades da fase de transição, numa fé fanática na perfectibilidade humana. A disposição de se jogar fora o que já havia, para então começar tudo de novo, impossibilitou a proposição de reformas socialistas graduais. Gabriel Cohn (1979) concluiu que a única saída para a racionalização do mundo, que encarcera a criatividade humana numa jaula de aço era, para Max Weber, a resignação, a escolha pessoal por um caminho ético e heroico; porém, ainda assim, o futuro da humanidade estaria fadado à tristeza e ao "desencantamento do mundo", pois mesmo a proposta socialista imporia uma racionalização não menos extremada.

Em oposição a isso, a proposta da economia solidária de forma alguma é a resignação, pois ela pode incorporar e reproduzir relações de dádiva (que pouco tem de racionalismo), apontando para a subversão da lei do valor. Ela recupera a crítica e a autocrítica marxiana e retoma a busca por um mundo melhor, mais ético e essencialmente solidário, como uma aposta cujo resultado é indeterminado, mas que nos coloca diante de uma escolha entre a passividade da descrença e a mobilização motivada pelo otimismo e pela esperança na humanidade. A economia solidária se apresenta como a retomada de uma longa caminhada, desesperançada no passado e, por longo tempo, tida como um sonho. Que seja uma utopia, não obstante uma utopia possível. Mas, como afirmou Lefebvre sobre outro assunto deveras controverso, ${ }^{27}$ isso é meramente uma hipótese estratégica...

\section{Referências bibliográficas}

BAMBIRA, Vânia. A teoria marxista da transição e a prática socialista. Brasília: Editora UnB, 1993.

BERTUCCI, Jonas de Oliveira. A economia solidária do pensamento utópico ao contexto atual: um estudo sobre experiências em Belo Horizonte". Dissertação (Mestrado em Economia)-Cedeplar/UFMG, 2005.

Tecnologia e solidariedade: notas introdutórias para uma discussão possível.

In: ENCONTRO DE ECONOMIA DA REGIÃO SUL, 7, 2004, Maringá. Anais... Maringá: Anpec Sul, 2004. p. 781-798.

CATANI, Antonio David (Org.). A outra economia. Porto Alegre: Veraz, 2003.

COHN, Gabriel. Crítica e resignação: fundamentos da sociologia de Max Weber. São Paulo: T. A. Queiroz, 1979.

ENGELS, F. Do socialismo utópico ao socialismo científico. 7. ed. São Paulo: Global Editora, 1985 [1880].

(27) A questão discutida por Lefebvre é a de como o conhecimento (saber) pode servir a reprodução das relações sociais de produção para além do modo de produção no qual essas relações nasceram (Lefebvre, 1978, p. 76). 
GODELIER, Maurice. Transição. In: ENCICLOPÉDIA Einaudi. Porto: Imprensa Nacional/Casa da Moeda, 1986 v. 7. p. 181-215.

KRUPPA, Sonia M. Portella (Org). Economia solidária e educação de jovens e adultos. Brasília: Inep, 2005.

LECHAT, Noelle M. P.; SCHIOCHET, Valmor. Economia da dádiva. In: CATANI, Antonio David (Org.). A outra economia. Porto Alegre: Veraz, 2003. p. 84-87.

LEFEBVRE, Henri. The survival of capitalism: reproduction of the relations of production. 2. ed. London: Allison \& Busby, 1978.

MANDEL, Ernest. A formação do pensamento econômico em Karl Marx: de 1843 até a redação de o Capital. Rio de Janeiro: Zahar Editores, 1968.

MANNHEIM, Karl. Liberdade, poder e planificação democrática. São Paulo: Mestre Jou, 1972.

MARX, K. O Capital. Livro I. Rio de Janeiro: Civilização Brasileira, 1980.

Crítica ao Programa de Gotha. Tradução de Sueli T. Barros Cassal. Porto Alegre: L\&M, 2002 [1875].

Prefácio. In: CONTRIBUIÇÃO à crítica da economia política. São Paulo: Abril, 1974. (Col. Os Pensadores).

. A guerra civil na França. Versão para e-book, Ridendo Castiag Moraes, 1999. (ebooksbrasil.com).

O 18 Brumário de Luis Bonaparte. São Paulo: Paz e Terra, 2002.

. A ideologia alemã. São Paulo: Martin Claret, 2005.

MARX, K.; ENGELS, F. A ideologia alemã. 7. ed. São Paulo: Editora Hucitec, 1989.

; _ Manifesto do partido comunista. Tradução de Sueli T. Barros Cassal. Porto Alegre: L\&M, 2002 [1848].

MAUSS, M. Ensaio sobre a dádiva”. In: MAUSS, M. Sociologia e antropologia. São Paulo: Cosac \& Naif, 2003.

MIGUEL, Luis Felipe. Utopias do pós-socialismo: esboços e projetos de reorganização radical da sociedade. Revista Brasileira de Ciências Sociais, v. 21, n. 61, 2006.

MORUS, Tomás. A utopia. Tradução de Paulo Neves. Porto Alegre: L\&PM, 2001[1516].

NEE, Victor. The role of the state in making markets. Journal of Institutional and Theoretical Economics, Washington, 1999.

ORWELL, George. A revolução dos bichos. Tradução de Heitor A. Ferreira. São Paulo: Globo, 2000 [1945].

PAULA, João Antônio de. Determinismo e indeterminismo em Marx. Revista Brasileira de Economia, Rio de Janeiro, n. 2, abr./jun. 1994. out./dez. 2000.

A dialética valores e preços. Revista de Economia Política, v. 20, n. 4 (80), 
Jonas de Oliveira Bertucci

PAULA, João Antônio de. O marxismo como pensamento crítico. Revista Soc. Bras. Economia Política, Rio de Janeiro, n. 9, dez. 2001.

POLANYI, Karl. A grande transformação: as origens de nossa época. Rio de Janeiro: Campos, 1980 [1944].

PROUDHON, Joseph-Pierre. O que é a propriedade? In: TEIXEIRA, Aloísio. Utópicos, heréticos e malditos. São Paulo: Record, 2002 [1840].

RODEGHERO, Carla Simone. Religião e patriotismo: o anticomunismo católico nos Estados Unidos e no Brasil nos anos da Guerra Fria. Revista Brasileira de História, São Paulo, v. 22, n. 44, 2002.

ROSANDA, Rossana. Poder y democracia en la sociedad de transición. In: SWEEZY, P. et al. Teoria del proceso de transicion. Córdoba, 1973. (Cuadernos de Pasado y Presente).

SCHUMPETER, Joseph. Capitalismo, socialismo e democracia. Rio de janeiro: Zahar Editores, 1984 [1942].

SINGER, Paul. Uma utopia militante: repensando o socialismo. Petrópolis, RJ: Vozes, 1998.

Introdução à economia solidária. São Paulo: Fundação Abramo, 2002.

A recente ressurreição da economia solidária no Brasil. In: SANTOS, Boaventura de Sousa (Org). Produzir para viver: os caminhos da produção não capitalista. Rio de Janeiro: Civilização Brasileira, 2002.

As grandes questões do trabalho no Brasil e a economia solidária. Revista Proposta, n. 97, jun./ago. 2003.

SWEEZY, Paul. Hacia un programa de estudio de la transición al socialismo". In: Presente).

et al. Teoria del proceso de transicion. Córdoba, 1973. (Cuadernos de Pasado y

TAUILE, José R. Do socialismo de mercado à economia solidária. In: SEMINÁRIO INTERNACIONAL "TEORIAS DE DESENVOLVIMENTO NO NOVO SÉCULO", Anais... jun. 2001.

VAN PARIJS, Philippe. Capitalismo de renda básica. Lua Nova, 32, p. 69-91, 1994.

VAZ, Henrique C. Lima. Sobre as fontes filosóficas do pensamento de Karl Marx. Boletim SEAF, Belo Horizonte, n. 2, 1982. 